\title{
Toxicity of cadmium and zinc to the cercarial activity of Diplostomum spathaceum (Trematoda: Diplostomidae)
}

\author{
Neil J. Morley, Mark Crane and John W. Lewis \\ School of Biological Sciences, Royal Holloway, University of London, Egham, Surrey, TW20 0EX, UK
}

Key words: Diplostomum spathaceum, cercariae, activity, cadmium, zinc

\begin{abstract}
The toxicity of cadmium and zinc at concentrations ranging from 0.1 to $100 \mu \mathrm{g} / \mathrm{l}$ was investigated against the activity of Diplostomum spathaceum (Rudolphi, 1819) cercariae. Over a $24 \mathrm{~h}$ exposure period a significant reduction in cercarial activity occurred in solutions of cadmium, zinc, and a mixture of cadmium and zinc at all concentrations. Reduced cercarial activity also occurred in all toxicant solutions compared with controls after only $6 \mathrm{~h}$ exposure indicating that cercariae were vulnerable during the period of maximum cercarial infectivity $(0-5 \mathrm{~h})$. The mechanisms of metal toxicity and their importance to parasite transmission are discussed.
\end{abstract}

Studies on the influence of toxic pollutants on parasites of aquatic organisms have increased in recent years with much focus on the pollutant effects on hostparasite interactions (Khan and Thulin 1991) and more recently on the free-living stages of parasites, especially the survival of digenean cercariae (e.g. Abd Allah et al. 1996, Soucek and Noblet 1998, Pietrock et al. 2001). However, most investigations have found that only limited mortality occurs in the presence of low concentrations of pollutants during the initial period of cercarial emergence, when cercariae demonstrate maximum infectivity to their target hosts. Consequently, attention has now begun to turn to other aspects of cercarial biology that may be more vulnerable to toxic effects.

The present study is part of a large multi-parameter ecotoxicology programme investigating the effects of cadmium and zinc toxicity on the cercariae of Diplostomum spathaceum (Rudolphi, 1819) (Morley et al. $2001,2002 \mathrm{a}, \mathrm{b})$, which is a ubiquitous parasite of fish throughout the UK (Chubb 1979). Cercarial life-span is temperature-dependent with maximum survival decreasing from $240 \mathrm{~h}$ at $4^{\circ} \mathrm{C}$ to $72 \mathrm{~h}$ at $20^{\circ} \mathrm{C}$ (Lyholt and Buchmann 1996). Optimal infectivity occurs between 0-5 h post-emergence and then declines exponentially to zero with age beyond $20 \mathrm{~h}$ (Whyte et al. 1991). Water hardness and temperature can influence the effects of cadmium and zinc on both survival (Morley et al. 2001) and tail loss (Morley et al. 2002a) of $D$. spathaceum cercariae. In addition, various combinations of cadmium and zinc mixtures can reduce the toxicity normally caused by single metal exposures (Morley et al. 2002b). A feature of these studies has been the increased survival of cercariae exposed to certain individual metal concentrations when compared with controls. Such results have been attributed to metal inhibition of glycogen utilisation, leading to reduced activity. Changes in patterns of cercarial tail loss have also been ascribed to changes in activity because more active cercariae place an increased stress on the bodytail linkage, causing it to break (Rea and Irwin 1992). Consequently, a study on the activity of metal-exposed cercariae over time was initiated, especially as little is known about the effect of toxic substances on cercarial activity. Bioactive com-pounds from seeds of the West African legume Millettia thonningii induced an increased state of unresponsive immobility with increasing concentration in cercariae of Schistosoma mansoni (Squire and Whitfield 1989, Perrett et al. 1994). Oshima et al. (1992) demonstrated that the insecticide Cartap hydrochloride caused a gradual decrease in the activity of cercariae of Gigantobilharzia sturniae over a three hour period. The horizontal swimming rate of Cryptocotyle lingua cercariae was found by Cross et al. (2001) to be reduced by heavy metals, both directly in experimental test conditions and also indirectly from cercariae emerging from snails collected from a metal-polluted environment when compared with controls.

Diplostomum spathaceum is an ideal species to study activity effects as cercariae demonstrate an intermittent swimming activity in which an active phase, with the cercariae swimming upwards, alternates with a passive phase, with the cercariae sinking down using the furca as a drag anchor (Haas 1992). Haas (1969) reported that the spontaneous activity of $D$. spathaceum cercariae was mainly affected by temperature and light intensity. Such intermittent behaviour between an active state (active swimming or passive dropping) and a non-active state (no movement off the test vessel bottom) allows the effects of metal toxicity to activity to be readily investigated.

The aim of the present study therefore is to investigate cadmium and zinc toxicity on the activity of $D$. spathaceum cercariae. Cadmium and zinc are related heavy metals which almost always occur together in polluted environments. They are widely used in industry 
and are released into aquatic ecosystems as a by-product of ore smelting (Hellawell 1986). In the UK, Vivian and Massie (1977) recorded metal concentrations chronically polluting the aquatic environment as high as 160 $\mu \mathrm{g} / \mathrm{l}$ for cadmium and $8800 \mu \mathrm{g} / \mathrm{l}$ for zinc.

\section{MATERIALS AND METHODS}

Stock solutions of $100 \mathrm{mg} / \mathrm{l}$ cadmium and zinc were prepared by dissolving either cadmium chloride $\left(\mathrm{CdCl}_{2} .5 /\right.$ $\left.2 \mathrm{H}_{2} \mathrm{O}\right)$ or zinc chloride $\left(\mathrm{ZnCl}_{2}\right)$ (Sigma Chemicals) in distilled water to give the correct concentration of metal ions. Test solutions were obtained by diluting stock solutions in distilled water and added to the test vessels at concentrations which gave final cercarial exposures of $0.1 \mu \mathrm{g} / 1,10 \mu \mathrm{g} / \mathrm{l}$, and 100 $\mu \mathrm{g} / \mathrm{l}$. Synthetic hard water $\left(250 \mathrm{mg} / \mathrm{CaCO}_{3}, \mathrm{pH} 8.00\right)$ was prepared using procedures described by HMSO (1969).

Samples of test solutions were analysed for metal loss from test water incubated at $20^{\circ} \mathrm{C}$ in metal concentrations ranging from $10 \mu \mathrm{g} / \mathrm{l}$ to $100 \mu \mathrm{g} / \mathrm{l}(0.1 \mu \mathrm{g} / \mathrm{l}$ was below the limit of detection) after $24 \mathrm{~h}$. Solutions were analysed on a Perkin Elmer Optima 3300 Inductively Coupled Plasma-Atomic Emission Spectrometer which was calibrated with a $1 \%$ nitric acid blank and a standard consisting of $1000 \mu \mathrm{g} / \mathrm{l}$ of cadmium and zinc in $1 \%$ nitric acid. The accuracy of data, which was assessed by analysing certified reference material (NIST SRM 1643d) along with the samples under study, had a relative error of $0.00037 \%$ for cadmium and $0.00065 \%$ for zinc.

Lymnaea stagnalis (Linnaeus), naturally infected with $D$. spathaceum, was collected from Dinton Pastures Country Park, Reading, UK (National Grid Reference SU779724), and maintained in aerated aquaria at $20^{\circ} \mathrm{C}$. Cercariae were identified according to morphological criteria described by Niewiadomska (1986). Although L. stagnalis appears to be an atypical host for $D$. spathaceum in some parts of mainland Europe, within the UK it is widely utilised along with $L$. peregra and L. palustris by this digenean (Chappell 1995). Toxic effects were investigated by placing 24 cercariae, with a maximum age of $20 \mathrm{~min}$, individually into wells of a flatbottomed microtitre plate (Life Sciences International) containing $300 \mu \mathrm{l}$ of hard water with an appropriate concentration $(0.1 \mu \mathrm{g} / \mathrm{l}, 10 \mu \mathrm{g} / \mathrm{l}, 100 \mu \mathrm{g} / \mathrm{l})$ of the test solution (cadmium, zinc, cadmium/zinc mixture) or a control of distilled water added.

Cercariae were maintained in a darkened room at $20^{\circ} \mathrm{C}$ and kept under constant illumination with a cold light source (light intensity 500 lux). Four replicates of each treatment were used and the number of active (active swimming or passive dropping) or non-active (no movement off the test vessel bottom) cercariae was observed at $3 \mathrm{~h}$ intervals for $24 \mathrm{~h}$. If decaudation or death occurred, cercariae were no longer observed for activity from that time-point onwards. Observations were undertaken using a long-arm stereo dissecting microscope set up above the light source. The focusing mount was left unscrewed from the support pillar and rested on the stopper ring. This allowed free movement of the focusing mount to observe individual cercariae along two rows of the microtitre plate without any disturbance of the parasites. Results were analysed with the SPSS computer package using a repeated measures ANOVA for toxicity effects over the $24 \mathrm{~h}$ test period and by Tukey's significant difference test for toxicity effects after $6 \mathrm{~h}$ (the nearest time point to the $5 \mathrm{~h}$ age limit of maximum cercarial infectivity).

\section{RESULTS}

A small amount of dissolved metal loss over $24 \mathrm{~h}$ occurred with all metals in the test solutions, although this did not exceed more than $10 \%$ for any exposure.

Control D. spathaceum cercarial activity over the test period demonstrated a gradual decline with approximately $40 \%$ of the population still active after $24 \mathrm{~h}$ (Fig. 1). Exposure to heavy metals caused an initial rapid drop in activity over the first $3 \mathrm{~h}$ followed by a slower reduction in activity up to $24 \mathrm{~h}$ (Fig. 1). After $24 \mathrm{~h}$ approximately $20 \%$ of the toxicant-exposed cercarial population were still active. All metal exposures at all concentrations were significantly different from controls during the test period (repeated measures ANOVA $F \geq 25.825, \mathrm{p} \leq 0.002$ ). However, there was no significant difference in the extent of reduced activity between the three metal solutions in any of the three test concentrations (repeated measures ANOVA F $\leq 5.674, \mathrm{p} \geq 0.055$ ). After $6 \mathrm{~h}$ the activity of cercariae in all metal solutions and at all concentrations was significantly lower than controls (Tukey's test $\mathrm{p} \leq$ 0.043).

\section{DISCUSSION}

The present study has demonstrated that cercarial activity in Diplostomum spathaceum declines over time and that heavy metals can rapidly and significantly reduce such activity, even at low concentrations. A decrease in activity under control conditions is related to the utilisation of the finite glycogen reserve. Anderson and Whitfield (1975) demonstrated that the rate of change of cercarial activity in Transversotrema patialense is directly proportional to the quantity of energy reserves present. Thus the rate of change, in non-stimulatory conditions, is always negative, due to the non-replaceable nature of food reserves (Anderson and Whitfield 1975).

The precise mechanism by which heavy metals may influence cercarial activity remains unknown. However, studies on the swimming behaviour of Proterometra macrostoma cercariae (Prior and Uglem 1979, Uglem and Prior 1983) suggest that a swimming pattern is central rather than reflex controlled, i.e. sensory feedback is not responsible for controlling rhythmic activity (Prior and Uglem 1979). The binding of heavy metals to areas associated with cercarial sensory receptors has been found to occur (Morley, unpublished observations) but it is unlikely, considering the above mentioned studies on cercarial activity, that this results in the reduced swimming activity of exposed $D$. spathaceum cercariae. 

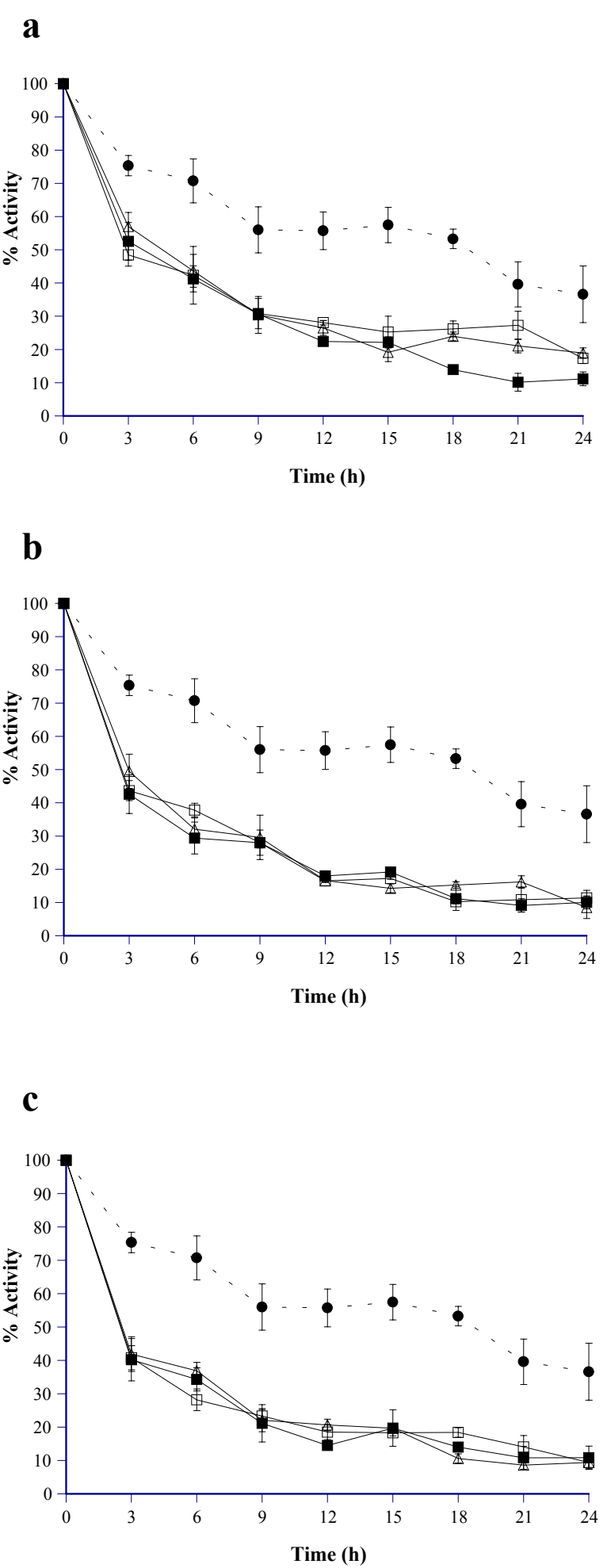

Fig. 1. Toxicity of $\mathbf{a}$ - cadmium, $\mathbf{b}-$ zinc, and $\mathbf{c}-$ cadmium/ zinc mixture to cercarial activity in Diplostomum spathaceum. Error bars are standard errors.

- control, $\square-0.1 \mu \mathrm{g} / 1, \mathbf{\Delta}-10 \mu \mathrm{g} / 1, \mathbf{\square}-100 \mu \mathrm{g} / 1$
Uglem and Prior (1983) identified transmitter substances involved in the stimulation of the neuromuscular activity controlling the swimming behaviour of P. macrostoma cercariae. Serotonin (5-HT) had a strong excitatory effect on electrical activity, whilst acetylcholine had an inhibitory effect. Cholinesterase activity, related to the presence of acetylcholine, has been reported in both the body and tail of Schistosoma mansoni cercariae (Fripp 1967, Bruckner and Voge 1974). It is possible that heavy metals in the present study may have affected the modulating action of acetylcholine on the neuromuscular activity underlying the swimming behaviour of $D$. spathaceum cercariae especially as acetyl cholinesterase activity is inhibited by cadmium in the tissues of the freshwater field crab Barytelphusa guerini (Reddy and Venugopal 1993).

The reduced cercarial activity demonstrated at all metal concentrations in the present study may be related to some of the changes in cercarial survival reported by Morley et al. (2001). Increased cercarial survival above that of controls was observed in a number of low concentrations which was dependent on water hardness and temperature and this may be related to the inhibition of glycogen utilisation. However, there was no pattern in the type of cercarial survival found from this study and included metal concentrations from the present investigation which could both increase and decrease cercarial survival. Therefore metal-exposed survival characteristics previously reported by Morley et al. (2001, 2002a, b) may be partially or totally independent of the effects on cercarial activity during the important initial $24 \mathrm{~h}$ exposure period. Further studies are therefore needed on the activity and survival characteristics of cercariae over the entire life-span to further elucidate whether these characteristics may be related products of a metal-induced inhibition of glycogen utilisation.

Nevertheless the substantial effects of heavy metals on the activity of $D$. spathaceum cercariae may have a major impact on transmission to the fish host. Cercariae lying passively at the bottom of their habitat will have a reduced chance of coming into contact with the host. Cercariae of $D$. spathaceum demonstrate a maximum infectivity only during the first $5 \mathrm{~h}$ post emergence (Whyte et al. 1991). Metal toxicity that affects cercarial activity during this period would be sufficient to cause a significant reduction in transmission. This effect can occur at concentrations that have previously been demonstrated (Morley et al. 2001, 2002a, b) to have little acute toxicity on the cercarial survival characteristics of $D$. spathaceum over the important initial $5 \mathrm{~h}$ post emergence period. 


\section{REFERENCES}

ABD ALLAH A.T., WANAS M.Q., THOMPSON S.N. 1996 The effects of lead, cadmium, and mercury on the mortality and infectivity of Schistosoma mansoni cercariae. J. Parasitol. 82: 1024-1026.

ANDERSON R.M., WHITFIELD P.J. 1975: Survival characteristics of the free-living cercarial population of the ectoparasitic digenean Transversotrema patialensis (Soparker, 1924). Parasitology 70: 295-310.

BRUCKNER D.A., VOGE M. 1974: The nervous system of larval Schistosoma mansoni as revealed by acetylcholinesterase staining. J. Parasitol. 60: 437-446.

CHAPPELL L.H. 1995: The biology of diplostomatid eyeflukes of fishes. J. Helminthol. 69: 97-101.

CHUBB J.C. 1979: Seasonal occurrence of helminths in freshwater fish. II. Trematodes. Adv. Parasitol. 17: 141-313.

CROSS M.A., IRWIN S.W.B., FITZPATRICK S.M. 2001: Effects of heavy metal pollution on swimming and longev-ity in cercariae of Cryptocotyle lingua (Digenea: Hetero-phyidae). Parasitology 123: 499-507.

FRIPP P.J. 1967: Histochemical localization of esterase activity in schistosomes. Exp. Parasitol. 21: 380-390.

HAAS W. 1969: Reizphysiologische Untersuchungen an Cercarien von Diplostomum spathaceum. Z. Vergleich. Physiol. 64: 254-287.

HAAS W. 1992: Physiological analysis of cercarial behavior. J. Parasitol. 78: 243-255.

HELLAWELL J.M. 1986: Biological Indicators of Freshwater Pollution and Environmental Management. Elsevier Applied Science Publishers, London, 546 pp.

HMSO 1969: Fish toxicity tests. H.M.S.O. Leaflet, No. Dd. 139779 K36 12/69.

KHAN R.A., THULIN J. 1991: Influence of pollution on parasites of aquatic animals. Adv. Parasitol. 30: 201-238.

LYHOLT H.C.K., BUCHMANN K. 1996: Diplostomum spathaceum: effects of temperature and light on cercarial shedding and infection of rainbow trout. Dis. Aquat. Org. 25: 169-173.

MORLEY N.J., CRANE M., LEWIS J.W. 2001: Toxicity of cadmium and zinc to Diplostomum spathaceum (Trematoda: Diplostomidae) cercarial survival. Int. J. Parasitol. 31: 1211-1217.

MORLEY N.J., CRANE M., LEWIS J.W. 2002a: Toxicity of cadmium and zinc to cercarial tail loss in Diplostomum spathaceum (Trematoda: Diplostomidae). Parasitology 125: 293-301.

MORLEY N.J., CRANE M., LEWIS J.W. 2002b: Toxicity of cadmium and zinc mixtures to Diplostomum spathaceum (Trematoda: Diplostomidae) cercarial survival. Arch. Environ. Contam. Toxicol. 43: 28-33.
NIEWIADOMSKA K. 1986: Verification of the life-cycles of Diplostomum spathaceum (Rudolphi, 1819) and D. pseudospathaceum Niewiadomska, 1984 (Trematoda, Diplostomidae). Syst. Parasitol. 7: 23-31.

OSHIMA T., KITAGUCHI T., SAITO K., KANAYAMA A. 1992: [Studies on the epidemiology of avian schistosome dermatitis caused by the cercariae of Gigantobilharzia sturniae.] Jpn. J. Parasitol. 41: 194-201. (In Japanese.)

PERRETT S., WHITFIELD P.J., BARTLETT A., SANDERSON L. 1994: Attenuation of Schistosoma mansoni cercariae with a molluscicide derived from Millettia thonningii. Parasitology 109: 559-563.

PIETROCK M., MEINELT T., MARCOGLIESE D.J., STEINBERG C.E.W. 2001: Influence of aqueous sediment extracts from the Oder River (Germany/Poland) on survival of Diplostomum sp. (Trematoda: Diplostomidae) cercariae. Arch. Environ. Contam. Toxicol. 40: 327-332.

PRIOR D.J., UGLEM G.L. 1979: Behavioural and physiological aspects of swimming in cercariae of the digenetic trematode, Proterometra macrostoma. J. Exp. Biol. 83: 239-247.

REA J.G., IRWIN S.W.B. 1992: The effect of age, temperature, light quantity and wavelength on the swimming behaviour of the cercariae of Cryptocotyle lingua (Digenea: Heterophyidae). Parasitology 105: 131-137.

REDDY S.L.N., VENUGOPAL N.B.R.K. 1993: Effect of cadmium on acetylcholinesterase activity and oxygen consumption in a freshwater field crab, Barytelphusa guerini. J. Environ. Biol. 14: 203-210.

SOUCEK D.J., NOBLET G.P. 1998: Copper toxicity to the endoparasitic trematode (Postdiplostomum minimum) relative to physid snail and bluegill sunfish intermediate hosts. Environ. Toxicol. Chem. 17: 2512-2516.

SQUIRE B.J., WHITFIELD P.J. 1989: Millettia thonningii: a rapid knockdown cercaricide for schistosome cercariae. Phyt. Res. 3: 112-114.

UGLEM G.L., PRIOR D.J. 1983: Control of swimming in cercariae of Proterometra macrostoma (Digenea). J. Parasitol. 69: 866-870.

VIVIAN C.M.G., MASSIE K.S. 1977: Trace metals in waters and sediments of the River Tawe, South Wales, in relation to local sources. Environ. Pollut. 14: 47-61.

WHYTE S.K., SECOMBES C.J., CHAPPELL L.H. 1991: Studies on the infectivity of Diplostomum spathaceum in rainbow trout (Oncorhynchus mykiss). J. Helminthol. 65: 169-178.

Accepted 29 November 2002 